九州大学学術情報リポジトリ

Kyushu University Institutional Repository

\title{
Genetic Evaluation of Carcass Traits of Commercial Steers at Different Slaughter End- points
}

Dang, Chang-Gwon

Hanwoo Experiment Station, National Institute of Animal Science, RDA

Lee, Seung-Hwan

Hanwoo Experiment Station, National Institute of Animal Science, RDA

Kim, Hyeong-Cheol

Hanwoo Experiment Station, National Institute of Animal Science, RDA

Lee, Jeong-Mook

Pyeongchang Youngwal Jungsun Livestock Cooperative

他

https://doi.org/10.5109/27360

出版情報：九州大学大学院農学研究院紀要. 58 (2)，pp. 295-300，2013-09. Faculty of Agriculture， Kyushu University

バージョン:

権利関係： 


\title{
Genetic Evaluation of Carcass Traits of Commercial Steers at Different Slaughter End-points
}

\section{Chang-Gwon DANG ${ }^{1}$, Seung-Hwan LEE ${ }^{1 *}$, Hyeong-Cheol KIM ${ }^{1}$, Jeong-Mook LEE ${ }^{3}$, Ki-Jun JEON ${ }^{1}$, Seong-Heum YEON ${ }^{1}$, Seong-Koo HONG ${ }^{2}$, Hee-Sul KANG ${ }^{1}$, Takafumi GOTOH ${ }^{4}$, Jun-Heon LEE $^{5}$ and Boh-Suk YANG ${ }^{2}$}

\author{
Kuju Agricultural Research Center, Kyushu University, Kuju 4045-4, \\ Taketa City, 878-020, Oita, Japan \\ (Received April 26, 2013 and accepted May 9, 2013)
}

\begin{abstract}
Carcass records, including pedigree, for 10,441 steers born from 2003 to 2008 and 21,711 animals total, were made available by the Pyengchang Youngwal Jungsun Livestock Cooperative. Data for each trait were adjusted for each of 5 end-points: age (EPA), back fat (EPB), carcass weight (EPC), eye muscle area (EPE), and marbling score (EPM), and adjustments were made by fitting a linear. Genetic parameters were estimated using ASREML, which uses an average information algorithm. At different slaughter end-points, heritability estimates for CWT (range $=0.25$ to 0.37 ) and EMA (range=0.17 to 0.33) were more significantly different than heritability estimates for BF (range=0.41 to 0.42) and MS (range=0.40 to 0.45). Genetic correlations between BF and CWT, EMA and CWT, and EMA and MS were positive, and those between BF and EMA and BF and MS were negative. The genetic correlation between CWT and MS yielded conflicting results. Correlations of sire breeding value for BF, CWT, EMA, and MS were in the range of 0.91 to $0.99,0.75$ to $0.93,0.72$ to 0.95 , and 0.90 to 0.99 , respectively, and those of the dam were in the range of 0.90 to $0.97,0.73$ to $0.94,0.71$ to 0.94 , and 0.91 to 0.99 , respectively. Further study will be needed to determine whether these alternative end-points result in a more accurate estimate of BV than the traditional age end-point.
\end{abstract}

Key words: breeding value, genetic correlation, Hanwoo, heritability, slauwghter end-points

\section{INTRODUCTION}

Hanwoo is a breed of cattle that is native to Korea and has been in use as draft animals for 5,000 years. Compared to Japanese Black cattle, the Hanwoo breed is known for their high marbling, having 15\%-23\% intramuscular fat (IMF) at final slaughter age (Kim et al., 2005). With regard to carcass value, the marbling score (MS), carcass weight (CWT), eye muscle area (EMA) and back fat thickness (BF) have the greatest influence on profit in the Korean beef industry. The current Hanwoo breeding program has achieved significant rates of genetic gain. For example, an estimate of annual gain over the last 10 years was $8 \mathrm{~kg}$ for CWT (2.6\% of the average phenotype) and $2.9 \mathrm{~cm}^{2}(3.8 \%)$ for EMA (NIAS, 2009). The rate of improvement for CWT was 0.4 based on genetic standards of deviation per year, which is much higher than the gains in MS (0.04 of a genetic standard deviation). Several factors contribute toward the low rate of gain for MS (Lee, 2011, PhD. thesis). Firstly, MS is estimated using a subjective score rather than an objective measurement such as chemical fat percentage. Secondly, candidate bulls $(n=400)$ are selected

\footnotetext{
Hanwoo Experiment Station, National Institute of Animal Science, RDA, Pyeongchang, 232-952, Korea

National Institute of Animal Science, R. D. A. Suwon, 441-706, Korea

3 Pyengchang Youngwal Jungsun Livestock Cooperative, Pyeongchang, Korea

${ }^{4}$ Kuju Agricultural Research Center, Kyushu University

5 Department of Animal Science and Biotechnology, Chungnam National University, Daejeon 305-764, Korea

* Corresponding Author (E-mail: slee46@korea.kr)
}

based on live weight (LWT) and average daily gain (ADG) through performance tests. Both LWT and ADG traits are highly correlated with CWT and EMA, but not with MS. Finally, marbling is a late maturing trait in cattle (Pethick et al., 2005). The premiums for high MS are prompting Korean farmers to extend the finishing period for Hanwoo beyond 30 months to further improve marbling scores. However, Korean proven (KPN) bulls are selected based on the breeding value estimated from carcass data slaughtered at 24 months of age from progeny tests. This may explain why genetic progress in CWT and EMA is much greater than in MS.

Currently, the progeny testing evaluation for the selection of KPN occurs every 6 months, and these bulls are distributed across the entire country. It is a wellstructured Hanwoo beef production system such as large scale of farm based progeny test that could be re-evaluated breeding value for KPN bulls and cows at different age structure.

In the United States of America, most breed associations currently adjust carcass traits to a constant age when computing breeding value, but age is seldom the primary criterion determining slaughter date in the current production systems (Shanks et al., 2001). It could be argued that the estimated carcass quality grade and external fat more closely represent the slaughter criteria. As for the genetic evaluation at different age structures, Cundiff et al. (1969) reported that carcass traits are known to be differently evaluated with different indirect genetic responses according to slaughter end-points, and Koch et al. (1995) reported that slaughter end-points can affect the expression of genetic and environmental differences. Because estimated breeding value is cur- 
rently adjusted to an end-point that does not closely match slaughter criteria, breeders need to know whether sires rank differently at alternative end-points (Shanks et al., 2001).

The objective of this study was to estimate genetic parameters and breeding value for carcass traits at different slaughter end-points and to determine whether the ranks of sires and cows vary in EBV when computed at different slaughter end-points.

\section{MATERIALS AND METHODS}

\section{Animals}

Carcass records for 10,442 steers born from 2003 to 2008 were made available by the Pyengchang Youngwal Jungsun Livestock Cooperative. Summary statistics for the data are provided in Table 1 . The completeness of pedigree information for up to 4 generations of Pyeongchang steers are provided in Figure 1. Going further back, the amount of ancestry information dramatically decreases.

Carcass traits analyzed were back fat thickness (BF), cold weight (CWT), ear muscle area (EMA) and marbling score (MS). CWT was measured after overnight chilling. EMA $\left(\mathrm{cm}^{2}\right)$ and BF (mm) were measured between the $12^{\text {th }}-13^{\text {th }}$ ribs. MS (graded on a scale from 1 to 9 where 1 is no intramuscular fat particles found, and 9 is abundant fat particles found) was subjectively evaluated by skilled practitioners at each of the slaughter houses.

\section{Statistical Models}

Genetic parameters were estimated for BF, CWT, EMA and MS using an animal model. Before variance component analyses, the GLM procedure of SAS (SAS Inst. Inc., Cary, NC) was used to test the significance of the fixed effects of year of slaughter, month of slaughter, owner, and the linear and quadratic effect of age (covariate). Data for each trait were adjusted to each of the 5 end-points: age (EPA), back fat (EPB), carcass weight (EPC), eye muscle area (EPE), and marbling score (EPM). Adjustments were made by fitting a linear covariate for the chosen end-point. For BF, CWT, EMA and MS were not undertaken when the adjustment was the trait itself.

The data were analyzed using an animal model. For calculation of genetic parameters, the model used was:

$$
\mathbf{y}=\mathbf{X} \beta+\mathbf{Z a}+\mathbf{e}
$$

where $\mathbf{y}$ is the vector of the observed phenotypes; $\beta$ is the vector of fixed effects, which included the contemporary group (year of slaughter, month of slaughter, owner); $\mathbf{a}$ is the vector of additive genetic effects; e is the vector of random error effects; $\mathbf{X}$ is the known incidence matrix associating fixed effects in $\beta$ with phenotypes in $\mathbf{y}$; and $\mathbf{Z}$ is the known incidence matrix associating random effects with phenotypes in $\mathbf{y}$.

Furthermore,

Table 1. Simple statistics for carcass traits

\begin{tabular}{lcrrrr}
\hline & $\mathrm{n}$ & Mean & \multicolumn{1}{c}{ S.D. } & \multicolumn{1}{c}{ Min } & \multicolumn{1}{c}{ Max } \\
\hline $\mathrm{AGE}^{1}$ & 10,442 & 929.65 & 56.13 & 701.00 & 1263.00 \\
$\mathrm{BF}^{2}$ & 10,442 & 13.66 & 5.31 & 1.00 & 49.00 \\
$\mathrm{CWT}^{3}$ & 10,442 & 424.47 & 43.81 & 172.00 & 614.00 \\
$\mathrm{EMA}^{4}$ & 10,442 & 92.01 & 10.01 & 9.00 & 141.00 \\
$\mathrm{MS}^{5}$ & 10,442 & 5.71 & 1.83 & 1.00 & 9.00 \\
\hline
\end{tabular}

${ }^{1} \mathrm{Age}=$ slaughter day; ${ }^{2} \mathrm{BF}=$ back fat thickness; ${ }^{3} \mathrm{CWT}=$ carcass weight; ${ }^{4} \mathrm{EMA}=$ eye muscle area; ${ }^{5} \mathrm{MS}=$ marbling score

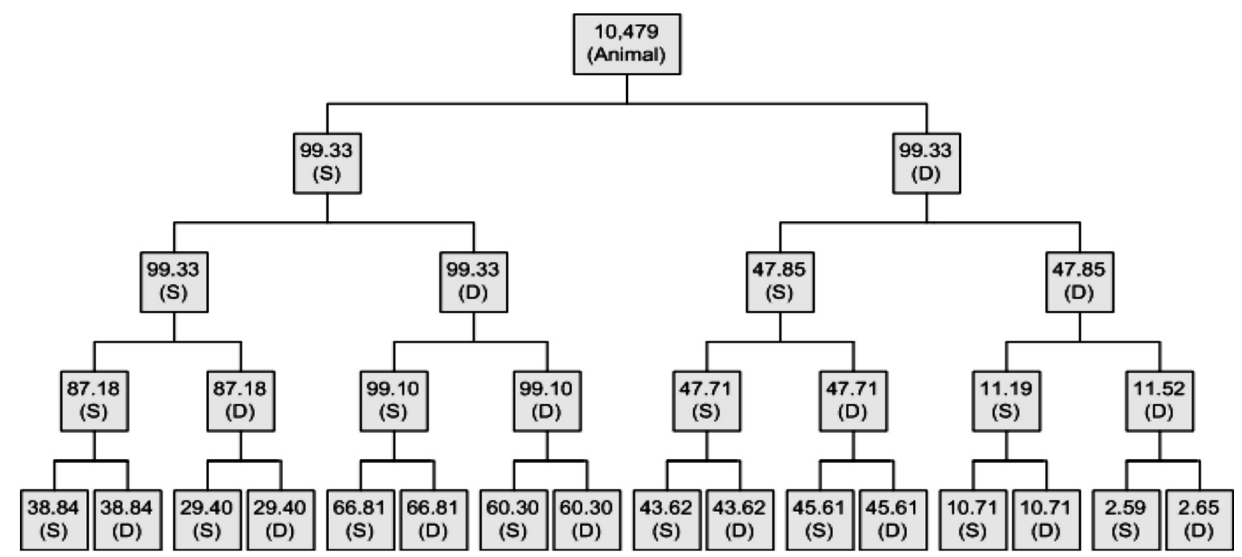

Fig. 1. Completeness of pedigree information for up to 4 generations of Pyeong Chang steer. S stands for sire and D for Dam. 


$$
\mathrm{E}[\mathrm{y}]=\mathrm{X} \beta ; \text { and }
$$$$
\operatorname{Var}\left[\begin{array}{l}
a \\
e
\end{array}\right]=\left[\begin{array}{cc}
A \sigma_{a}^{2} & 0 \\
0 & I \sigma_{e}^{2}
\end{array}\right]
$$

where $\mathrm{A}$ is the numerator relationship matrix of the 21,711 animals included in the pedigree, I is the identity matrix of proper order $\sigma_{a}^{2}$ is the variance due to additive genetic effects, and $\sigma_{a}^{2}$ is the variance due to random error.

Genetic parameters were estimated using ASREML (Gilmour et al., 2006), which uses an average information algorithm. The program routinely reports log-likelihood statistics, which were used for model comparison, whereas variance components were used to estimate phenotypic and genetic parameters. The animal variance component represented an estimate of the additive genetic variance $\left(\sigma_{a}^{2}\right)$, whereas the phenotypic variance $\left(\sigma_{p}^{2}\right)$ was obtained from the sum of all variance components. Heritability $\left(h^{2}\right)$ was computed as the ratio between the additive genetic and phenotypic variances.

To measure agreement between the carcass trait BV computed at different slaughter end-points, Spearman rank correlations (SAS Inst. Inc., Cary, NC) were computed among BV values estimated for the same trait at different slaughter end-points. This was done two ways using BV of the sire and dam.

\section{RESULTS AND DISCUSSION}

\section{Fixed Effect}

The source of the variation, degree of freedom, mean square and test of significance for each trait are shown in Table 2. The year of birth, month of birth and owner of farm were significant $(\mathrm{P}<0.05)$ for all traits. The linear and quadratic covariate for slaughter age was only non-significant for MS. Because the fixed effect and covariate were significant except for place of EMA and SD1 and SD2 of MS, the year of birth, month of birth, place, owner, linear covariate for slaughter age and quadratic covariate for slaughter age were included in the model.

\section{Heritability}

Heritability estimates for carcass traits at different slaughter end-points are shown in Table 3. At different slaughter end-points, heritability estimates for BF, CWT, EMA and MS ranged from 0.41 to 0.42 , from 0.25 to 0.37 , from 0.17 to 0.33 and from 0.40 to 0.45 , respectively. Differences between heritabilities for carcass traits based on age and weight covariates were smaller than other end-points. Heritability estimates for BF and MS differed slightly; however, those for CW and EMA differed greatly. This difference may be due to the effect of slaughter day, which ranged from 701 to 1,263 days. Heritability of BF and MS may have a smaller effect than CWT and EMA on day of slaughter. Our heritability estimates of

Table 2. Source of variation, degrees of freedom, mean square and test of significance for each trait

\begin{tabular}{|c|c|c|c|c|c|}
\hline Source & d.f & $\mathrm{BF}$ & CW & EMA & MS \\
\hline Year $^{1}$ & 6 & $890.81^{* *}$ & $86,761.89^{* *}$ & $3,189.48^{* * *}$ & $23.65^{* *}$ \\
\hline Month $^{2}$ & 11 & $268.13^{* *}$ & $2,952.50 *$ & $264.68^{* *}$ & $6.27^{*}$ \\
\hline Place $^{3}$ & 2 & $148.21^{* *}$ & $6,192.12^{*}$ & 45.27 & $31.73^{* *}$ \\
\hline Owner ${ }^{4}$ & 66 & $161.11^{* *}$ & $15,956.18^{* *}$ & $396.93 * *$ & $17.78^{* *}$ \\
\hline $\mathrm{SD}^{5}$ & 1 & $735.09 * *$ & $366,412.06^{* *}$ & $5,402.79 * *$ & 1.12 \\
\hline $\mathrm{SD} 2^{6}$ & 1 & $616.79 * *$ & $299,234.90 * *$ & $4,721.84^{* *}$ & 0.21 \\
\hline Error & 10,354 & 26.24 & 1542.37 & 93.19 & 3.19 \\
\hline
\end{tabular}

${ }^{1}$ AYear=year of birth; ${ }^{2}$ Month=month of birth; ${ }^{3}$ Place=Pyengchang, Youngwal, Jungsun; ${ }^{4} \mathrm{SD}=$ slaughter day (linear); ${ }^{5} \mathrm{SD} 2=$ slaughter day (quadratic); $*=\mathrm{p}<0.05 ; * *=\mathrm{p}<0.01$

Table 3. Heritability estimates for carcass traits at different slaughter end-points

\begin{tabular}{lcccc}
\hline \multirow{2}{*}{ End point } & \multicolumn{3}{c}{ Trait } \\
\cline { 2 - 5 } & BF & CWT & EMA & MS \\
\hline $\mathrm{EPA}^{1}$ & 0.42 & 0.32 & 0.26 & 0.44 \\
$\mathrm{EPB}^{2}$ & - & 0.25 & 0.20 & 0.42 \\
$\mathrm{EPC}^{3}$ & 0.42 & - & 0.33 & 0.45 \\
$\mathrm{EPE}^{4}$ & 0.41 & 0.37 & - & 0.40 \\
$\mathrm{EPM}^{5}$ & 0.41 & 0.28 & 0.17 & - \\
\hline
\end{tabular}

${ }^{1} \mathrm{EPA}=$ end point adjusted to age; ${ }^{2} \mathrm{EPB}=$ end point adjusted to backfat; ${ }^{3} \mathrm{EPC}=$ end point adjusted to carcass weight; ${ }^{4} \mathrm{EPE}=$ end point adjusted to ear muscle area; ${ }^{5} \mathrm{EPM}=$ end point adjusted to marbling score 
MS were higher than in other studies of Hanwoo cattle (Lee et al., 2000; Choy et al., 2005; Choy et al., 2008). This might have been due to scalar differences in MS; previous studies used a 1-5 or 1-7 scoring system, while we used a 1-9 scoring system.

When heritability estimates were computed at a constant age, heritability of CWT (0.32) was similar to those (0.32 and 0.33, respectively) reported by Shanks et al. (2001) and Rumph et al. (2007), and heritability of EMA (0.26) was similar to those reported by Shanks et al. (2001), Ríos-utrera et al. (2005) and Rumph et al. (2007) (0.26, 0.24 and 0.26, respectively). Choi et al. (2005), Choi et al. (2005) and Ríos-utrera et al. (2005) reported a heritability of $0.42,0.45$ and 0.40 , respectively, which was similar to the heritability found in the present study (0.44). However, heritability estimates computed at a constant age in this study were generally higher than those reported by other researchers (the difference was greater than 0.05).

When adjusted to a constant BF, heritability estimates for CW and EMA were lower than estimates previously reported (Choy et al., 2005; Shanks et al., 2001; Ríos-utrera et al., 2005; Rumph et al., 2007). However, heritability for MS was higher than previously reported. There was no reported heritability adjusted to a constant
EMA. Heritability estimates computed at a constant weight were higher than those reported by Shanks et al. (2001), Ríos-utrera et al. (2005) and Rumph et al. (2007). There were few reported carcass trait heritabilities adjusted to a constant marbling.

\section{Genetic, Phenotypic and Breeding Value Correlations}

Genetic and phenotypic correlations among carcass traits at different slaughter end-points are shown in Table 4. Genetic correlations between BF and CWT, EMA and CWT, and EMA and MS were positive, and genetic correlations between BF and EMA and BF and MS were negative. The genetic correlation between CWT and MS yielded conflicting results. The results of this study were similar to a genetic evaluation report of Hanwoo (NIAS, 2011) but low to high in magnitude. In comparison to several previous studies (Choy et al., 2005, Choy et al., 2008, Lee et al., 2000, Ríos-utrera et al., 2005, Rumph et al., 2007, and Shanks et al., 2001), the genetic correlation between EMA and BF were equally negative, but other genetic correlations were conflicting. These differences may be due to in breed groups, effects of the model, method of estimation, number of observations, measurement errors, and so on.

Table 4. Genetic and phenotypic correlations among carcass traits at different slaughter end-points

\begin{tabular}{|c|c|c|c|c|}
\hline Trait and end-point & BF & CWT & EMA & MS \\
\hline \multicolumn{5}{|l|}{ BF } \\
\hline EPA & - & 0.3506 & 0.0714 & 0.0810 \\
\hline $\mathrm{EPB}$ & - & - & - & - \\
\hline $\mathrm{EPC}$ & - & - & -0.1380 & 0.0510 \\
\hline $\mathrm{EPE}$ & - & 0.3671 & - & 0.0585 \\
\hline EPM & - & 0.3259 & 0.0366 & - \\
\hline \multicolumn{5}{|l|}{ CWT } \\
\hline $\mathrm{EPA}$ & 0.3053 & - & 0.5370 & 0.1077 \\
\hline $\mathrm{EPB}$ & - & - & 0.5932 & 0.1215 \\
\hline $\mathrm{EPC}$ & - & - & - & - \\
\hline EPE & 0.5012 & - & - & 0.0037 \\
\hline EPM & 0.4331 & - & 0.5614 & - \\
\hline \multicolumn{5}{|l|}{ EMA } \\
\hline $\mathrm{EPA}$ & -0.2892 & 0.3150 & - & 0.2156 \\
\hline $\mathrm{EPB}$ & - & 0.2473 & - & 0.2407 \\
\hline $\mathrm{EPC}$ & -0.4345 & - & - & 0.1858 \\
\hline $\mathrm{EPE}$ & - & - & - & - \\
\hline EPM & -0.1689 & 0.1704 & - & - \\
\hline \multicolumn{5}{|l|}{ MS } \\
\hline EPA & -0.2307 & 0.0671 & 0.6201 & - \\
\hline $\mathrm{EPB}$ & - & 0.0511 & 0.6057 & - \\
\hline $\mathrm{EPC}$ & -0.2690 & - & 0.6128 & - \\
\hline $\mathrm{EPE}$ & -0.1984 & -0.2871 & - & - \\
\hline EPM & - & - & - & - \\
\hline
\end{tabular}

phenotypic correlations=above the diagonal; genetic correlations=below the diagonal 
Correlations of breeding value for carcass traits at different slaughter end-points are shown in Table 5. At different slaughter end-points, correlations of sire breeding value for $\mathrm{BF}, \mathrm{CWT}, \mathrm{EMA}$, and MS were in the range of 0.91 to $0.99,0.75$ to $0.93,0.72$ to 0.95 , and 0.90 to 0.99 , respectively, and correlations of dam breeding value for $\mathrm{BF}$, CWT, EMA, and MS were in the range of 0.90 to $0.97,0.73$ to $0.94,0.71$ to 0.94 , and 0.91 to 0.99 , respectively. Correlations of $\mathrm{BV}$ for the same trait adjusted to different end-points from the sire and dam were small in this study. However, the correlation of CWT and EMA differed greatly with BF and MS. This may be due to heritability estimations for CWT and EMA.

Few studies (Lee et al., 2000; Choy et al., 2005; Choy et al., 2008) have compared estimates of heritability and genetic correlations for carcass traits adjusted to different slaughter end-points in Hanwoo cattle. Therefore, further study will be needed to determine whether these alternative end-points result in a better estimate of BV than the traditional age end-point.

\section{ACKNOWLEDGMENT}

This study was "Development of breeding model for eating quality traits in Hanwoo" funded by the National Institute of Animal Science (NIAS), the Rural Development Administration (RDA), Suwon, Republic of Korea. Performance records with pedigree information from the Pyengchang Youngwal Jungsun Livestock Cooperative were used in this research. The authors wish to give thanks to the RDA for funding and Pyengchang Youngwal Jungsun Livestock Cooperative for their endeavors to collect and provide data.

\section{REFERENCES}

Choy, Y. H., C. W. Lee, H. C. Kim, S. B. Choi, J. G. Choi, and J. M. Hwang. 2008 Genetic models for carcass traits with different slaughter endpoints in selected Hanwoo herds. Asian-Aust. J. Anim. Sci. 21, No. 9: 1227-1232

Choy, Y. H., H. B. Yoon, S. B. Choi, and H. W. Chung. 2005 Genetic analysis of carcass traits in Hanwoo with different slughter end-points. J. Anim. Sci. \& Tecchnol. (Kor.) 47(5): 703-710

Cundiff, L. V., K. E. Gregory, R. M. Koch, and G. E. Dickerson. 1969 Genetic variation in total and differential growth of carcass components in beef cattle. J. Anim. Sci. 29: 233-244

Gilmour, A. R., B. J. Gogel, B. R. Cullis, and R. Thompson. 2009 ASREML User, Guide Release 3.0, VSN International Ltd, Hemel Hempstead, UK

Kim, K. H., Lee, J. H., Oh, Y. G., Kang, S. W., Lee, S. C., Park, W. Y., and Ko, Y. D. 2005 The optimal TDN levels of concentrates

Table 5. Correlations of breeding value for carcass traits at different slaughter end-points

\begin{tabular}{|c|c|c|c|c|c|}
\hline Trait and end-point & EPA & EPB & EPC & EPE & EPM \\
\hline \multicolumn{6}{|l|}{$\mathbf{B F}$} \\
\hline EPA & - & - & 0.9378 & 0.9751 & 0.9785 \\
\hline $\mathrm{EPB}$ & - & - & - & - & - \\
\hline $\mathrm{EPC}$ & 0.9495 & - & - & 0.9063 & 0.9240 \\
\hline $\mathrm{EPE}$ & 0.9718 & - & 0.8984 & - & 0.9857 \\
\hline $\mathrm{EPM}$ & 0.9688 & - & 0.9046 & 0.9719 & - \\
\hline \multicolumn{6}{|l|}{ CWT } \\
\hline $\mathrm{EPA}$ & - & 0.8592 & - & 0.7524 & 0.8738 \\
\hline EPB & 0.8622 & - & - & 0.7889 & 0.8867 \\
\hline $\mathrm{EPC}$ & - & - & - & - & - \\
\hline EPE & 0.8038 & 0.7291 & - & - & 0.9332 \\
\hline EPM & 0.9118 & 0.8431 & - & 0.9352 & - \\
\hline \multicolumn{6}{|l|}{ EMA } \\
\hline EPA & - & 0.9479 & 0.8493 & - & 0.7624 \\
\hline $\mathrm{EPB}$ & 0.9429 & - & 0.8348 & - & 0.7810 \\
\hline EPC & 0.9213 & 0.8852 & - & - & 0.7248 \\
\hline $\mathrm{EPE}$ & - & - & - & - & - \\
\hline EPM & 0.7252 & 0.7064 & 0.7114 & - & - \\
\hline \multicolumn{6}{|l|}{ MS } \\
\hline $\mathrm{EPA}$ & - & 0.9902 & 0.9931 & 0.8980 & - \\
\hline $\mathrm{EPB}$ & 0.9792 & - & 0.9861 & 0.8990 & - \\
\hline EPC & 0.9974 & 0.9778 & - & 0.9160 & - \\
\hline EPE & 0.9079 & 0.9169 & 0.9166 & - & - \\
\hline EPM & - & - & - & - & - \\
\hline
\end{tabular}

Correlations from sires above diagonal, and correlations from dams below diagonal. All correlations significantly different from zero $(\mathrm{P}<0.0001)$ 
and slaughter age in Hanwoo steers. J. Anim. Sci. Technol. (Kor.). 47(5): 731-744

Koch, R. M., K. E. Gregory, and L. V. Cundiff. 1995 Genetic aspects of beef carcass growth and development. Page 9 in proc. 5th Genetic Prediction Workshop, Kansas City, MO

Lee, J. W., S. B. Choi, J. S. Kim, J. F. Keown and L. D. Van Vleck. 2000 Parameter estimates for genetic effects on carcass traits of Korean native cattle. J. Anim. Sci. 78: 1181-1190

Lee, S. H. 2011 Genome analysis to identify QTL and genes affecting carcass traits in Hanwoo (Korean cattle). PhD. thesis

NIAS (National Institute of Animal Science). 2009 Annual report for Hanwoo genetic evaluation, p. 17

NIAS (National Institute of Animal Science). 2011 Genetic evaluation report of Hanwoo vol. 23

Pethick, D. W., D. N. D'Souza, F. R. Dunshea and G. S. Harper.
2005 Fat metabolism and regional distribution in ruminants and pigs-influences of genetics and nutrition. Recent Adv. Anim. Nutr. Austr. 15: 39-45

Ríos-Utrera, A., L. V. Cundiff, K. E. Gregory, R. M. Koch, M. E. Dikeman, M. Koohmaraie, and L. D. Van Vleck. 2005 Genetic analysis of carcass traits of stter adjusted to age, weight, or fat thickness slaughter endpoints. J. Anim. Sci. 83: 764-776

Rumph, J. M., W. R. Shafer, D. H. Crews, Jr., R. M. Enns, R. J. Lipsey, R. L. Quaas, and E. J. Pollak. 2007 Genetic evaluation of beef carcass data using different endpoint adjustments. J. Anim. Sci. 85: 1120-1125

SAS, Ver. 9.2, SAS Inst, Inc., Cary, NC

Shanks, B. C., M. W. Tess, D. D. Kress, and B. E. Cunningham 2001 Genetic evaluation of carcass traits in Simmental-sired cattle at different slaughter end points. J. Anim. Sci. $\mathbf{7 9}$ : 595-604 